September 26, 2013

\title{
Social Insurance Networks
}

\author{
Simen Markussen and Knut Røed*
}

The Ragnar Frisch Centre for Economic Research

\begin{abstract}
Based on administrative panel data from Norway, we examine how social insurance claims spread among neighbors and former schoolmates. We use a fixed effects methodology that accounts for endogenous group formation, contextual interactions, and time-constant as well as time-varying confounders. We report evidence that social insurance claims are contagious. There are significant local peer effects both in the overall use of social insurance and in the propensity to use one particular social insurance program rather than another. The magnitudes of the estimated peer effects rise consistently with measures of geographical and relational closeness.
\end{abstract}

Keywords: social interaction, social multiplier, work norms, peer effects.

JEL Classification: C31, H55, I38,

* This paper is part of the project "Social Insurance and Labor Market Inclusion in Norway”, funded by the Norwegian Research Council (grant \#202513). Data made available by Statistics Norway have been essential for the research project. Thanks to Bernt Bratsberg, Oddbjørn Raaum, three anonymous referees, and the Editor for valuable comments. Correspondence to: Knut Røed, the Ragnar Frisch Centre for Economic Research, Gaustadalléen 21, 0349 Oslo, Norway. E-mail: knut.roed@frisch.uio.no. 


\section{Introduction}

The purpose of this paper is to examine endogenous social interaction in social insurance (SI) claims. The paper is motivated by two observations. First, there has been a conspicuous - yet basically unexplained - rise in social security dependency in many countries, particularly related to health problems; see, e.g., Duggan and Imberman (2006), Bratsberg et al. (2013), and Burkhauser and Daly (2011). And second, there tend to be correspondingly large and unexplained geographical disparities in dependency rates as well as in attitudes toward social insurance both within and across countries; see McCoy et al. (1994), OECD (2010), and Eugster et al. (2011). Although far from offering a complete explanation, these empirical patterns may be easier to understand if SI claim propensities exhibit path-dependency due to peer effects; see, e.g., Bertrand et al. (2000) and Durlauf (2004). Such peer effects could result from transmission of work norms or changes in the stigma attached social insurance claims (Moffitt, 1983; Lindbeck, 1995; Lindbeck et al., 1999; 2003), or they could arise from the transfer of information about eligibility rules, application procedures, and acceptance probabilities (Aizer and Currie, 2004), or about job opportunities (Ioannides and Loury, 2004).

While social interaction effects have been extensively analyzed from a theoretical perspective, empirical analysis has been held back by methodological difficulties and lack of appropriate data. The fundamental empirical challenge is to disentangle endogenous interaction from other sources of correlation between individual and group behavior, such as endogenous group formation and unobserved confounders; see Manski (1993). As shown by our brief literature review in the next section, the existing empirical evidence on SI contagion is scant and, with a few important exceptions, limited to ethnic minorities. Existing evidence is also confined to very specific SI programs, making it difficult to assess whether it has captured peer effects in overall SI dependency or in the tendency to use one specific SI program 
rather than another. The policy implications following from these two competing interpretations are clearly different.

In the present paper, we examine social interaction effects within different kinds of networks - or peer groups - i.e., neighbors, schoolmates, and ethnic minorities. The key research question we ask is whether - and to what extent - an agent's likelihood of claiming any form of tax-financed income support is causally affected by the level of claims recorded within the various types of networks the agent relates to, conditional on the claim patterns prevailing elsewhere in the economy. In addition, we examine peer effects in the propensity to use one type of SI program rather than another. The question of interest here is whether - and to what extent - the distribution of SI claims between "disability-related" and "unemployment-related” programs within a network affect the group members' propensities to claim benefits from these program types.

We use an extraordinarily rich and detailed panel data set from Norway, covering the whole working-age population over age 17 . We exploit the richness of the data to set up empirical models in which we control for the various confounding and sorting problems that often undermine the credibility of reported social interaction effects. In contrast to much of the existing literature, we do not rely on either instrumental variables or movements between networks, but instead use individual fixed effects to remove the influence of time-constant confounders and contextual interactions, and flexible time functions to control for networkspecific shocks and sorting problems that are not eliminated by the individual fixed effects. A novel feature of our empirical approach is that we examine how SI interaction effects vary with geographical as well as relational distance, i.e., we are not only interested in effects of peer-group behavior per se, but also in the way the interaction effects vary as we move from “close” to more "distant” network members. 
Our findings confirm the empirical relevance of endogenous social interaction. We present several empirical results indicating that individuals' own SI claim propensities are significantly affected by claim patterns among peers, and that the effects grow with relational closeness. For example, we find that an exogenous change in average SI claims within a group of adults who at some time went to the same junior high school together generates cumulative knock-on effects amounting to around $25 \%$ of the initial change. But the peer effect is much larger among same-level-same-sex schoolmates than it is among more "distant" schoolmates. Within small neighborhoods, we find that an exogenous change in SI claims entails additional knock-on effects amounting to $23 \%$ of the initial change. Again, the effect is much larger among similar than among dissimilar neighbors, and also larger among geographically close than among geographically more distant neighbors. We find particularly strong interaction effects within ethnic networks, defined as immigrants from a common low-income source country who reside in the same local area. The cumulative peer effect for these groups is estimated to around $44 \%$. The peer effects do not cross ethnic boundaries, however; a rise in SI dependency among immigrants from other low-income countries in the same local area has no effect at all.

Our results also indicate considerable scope for substitution between different SI programs. When we distinguish between "disability-related" and "unemployment-related" SI claims, we find that an exogenous rise in a peer group's use of one of these program types has a much larger effect on group member's same-type-claims than it has on their overall use of SI. A significant part of the additional SI claims is thus offset by a reduction in claims of the other type. An important implication of this finding is that empirical approaches focusing on a single program only will tend to exaggerate the peer effects in overall SI dependency. Peer effects are important both for the overall level of SI claims and for the allocation of claims across SI programs. 
Finally, we show that peers affect SI claim propensities among previous non-claimants (the entry decisions) as well as among more experienced claimants (the continuation decisions). This suggests that the peer-effects not only mirror a process of information-sharing, but also impacts on the utility associated with being in a state of benefit recipiency. And while peers' use of competing (other-type) SI programs has a negative (substitution) effect on entry into each program type, it has a positive impact on continuation. We conclude from this that the peer effects identified in this paper to a large extent reflect the propagation of work-norms or the stigma associated with being an SI claimant.

\section{Related literature}

There is by now a large and rapidly expanding empirical literature on social interactions within economics, covering a wide range of topics; see, e.g. Durlauf (2004) or Ioannides and Loury (2004) for recent reviews and Blume et al. (2010) for a comprehensive overview of the various identification strategies that have been applied in the literature. The latter paper concludes that the current research frontier still involves efforts to achieve identification in the presence of the three challenges originally highlighted by Manski (1993): i) to differentiate between social interactions that derive from direct interdependencies between choices (endogenous interactions) and social interactions that derive from predetermined social factors (contextual interactions), ii) to deal with the presence of group-level unobserved heterogeneity (confounding factors), and iii) to deal with the presence of endogenous formation of the groups that act as carriers of social interactions.

There is also a growing empirical literature on peer-effects in the utilization of public transfers. Bertrand et al. (2000) examine the role of welfare participation within local networks in the U.S., defined by language spoken. Their empirical strategy is to investigate whether belonging to a language group with high welfare use has larger effects on own wel- 
fare use the more a person is surrounded by people speaking one's own language. They find that this is indeed the case, and conclude that networks are important for welfare participation. Aizer and Currie (2004) use a similar approach to study network effects in the utilization of publicly funded prenatal care in California, with groups defined by race/ethnicity and neighborhoods. They conclude that group behavior does affect individual behavior. Furthermore, they show that the identified network effects cannot be explained by information-sharing, since the effects persist even for women who had used the program before. Conley and Topa (2002) examine the spatial patterns of unemployment in Chicago, and find that local variations are consistent with network effects operating along the dimensions of race and geographical and occupational proximity.

The recent literature also includes a number of studies outside the U.S. Stutzer and Lalive (2004) examine the pattern of unemployment duration in Switzerland, and find that strong local work norms - as measured by voting behavior in a referendum on the level of unemployment insurance - tend to coincide with short unemployment durations. Hesselius et al. (2009) use experimental data from Sweden to examine the extent to which co-workers affect each other's use of sick-pay. The experiment they use implied that a randomly selected group of workers were subject to more liberal rules regarding the need for obtaining a physician's certificate to prove that their absence from work was really caused by sickness. Hesselius et al. (2009) show that the reform caused absenteeism to rise both among the treated and the non-treated workers, and that the latter effect was larger the larger was the fraction of treated workers at the workplace. Peer effects in absenteeism are also examined by Ichino and Maggi (2000). Their empirical strategy is to study how workers who move between branches in a large Italian bank adapt to the prevailing absence cultures in the destination branches. The key finding is that workers adjust own absence behavior in response to the absence level among their new colleagues. A similar approach has been used by Bradley et al. 
(2007) to study absenteeism among school teachers in Queensland, Australia. And again, the finding is that the absenteeism of movers to some extent adapts to the prevailing absence culture at their new school. Åslund and Fredriksson (2009) examine peer effects in welfare use among refugees in Sweden, exploiting a refugee placement policy which generates the rarity of exogenous variation in peer group composition. A key finding of the paper is that longterm welfare dependency among refugees is indeed higher the more welfare-dependent the community is in the first place.

Empirical evidence on peer effects in the utilization of social insurance in Norway is provided in three recent papers by Rege et al. (2012), Bratberg et al. (2012), and Dahl et al. (2013), respectively. Rege et al. (2012) investigate neighborhood peer effects in disability insurance program participation among older workers by means of an instrumental variables strategy. Their key idea is that since the probability of disability program entry in Norway has been shown to be strongly affected by job loss (Rege et al.. 2009; Bratsberg et al., 2013), exogenous events of layoff in a person's neighborhood, e.g., caused by firm closure, can be used to instrument the neighbors' disability program participation (with proper controls for local variations in labor demand). Based on this strategy, Rege et al. (2012) estimate a sizable network effect implying that a 1 percentage point exogenous increase in similarly aged neighbors' disability program participation rate generates an additional increase of 0.3-0.4 percentage points as a result of network effects. Bratberg et al. (2012) and Dahl et al. (2013) both assess the transmission of disability pension recipiency within families, but with completely different empirical strategies. Bratberg et al. (2012) take the view that the intergenerational transmission of, say, work norms, operates through "exposure”, and identify the social interaction effect by comparing siblings who, due to differences in age, to varying extent shared household with their parent after the disability pension was granted. Their finding confirms that longer exposure to a parent claiming disability insurance indeed raises the probability that 
the offspring also claims such benefits later on. Dahl et al. (2013), on the other hand, compare children who were all adults at the time of a parent's application for disability insurance, and uses what they claim is a random assignment component in the decision process - the assignment of judges to applicants whose cases were initially denied - as the source of identification of the intergenerational transmission mechanism. Again, the key finding is that a parent's entry to the disability insurance program significantly raises the probability that their offspring also enter the program.

While representing important insights to the existence of peer effects in SI claims, these papers also illuminate the limitations associated with each specific empirical approach. For example, although Rege et al. (2012) build on an instrumental variable strategy, identification ultimately ends up being dependent observed control variables, since the presumed exogenous layoff of neighbors may have resulted from local economic circumstances that also affected other workplaces in the neighborhood, and since mass-layoffs also may have had direct knock-on effects on other businesses in a local area. And, although Dahl et al. (2013) use a random assignment methodology, there has in reality never been a genuine randomization of judges to disability insurance cases in Norway. Hence, one has to believe that the administrative procedures actually used (over a very long period of time) ensure a sufficient degree of randomness, which is quite difficult to verify. Most importantly, what all the pieces of Norwegian evidence have in common is that they focus almost exclusively on the transmission of permanent disability insurance claims. We will argue that this is an unfortunate limitation, since permanent disability insurance typically either substitutes for or is preceded by other social insurance programs, such as temporary disability insurance, sick pay, unemployment benefits, or social assistance. A considerable degree of substitutability between unemployment and disability insurances has been established in several empirical papers; see, e.g., Black et al. (2009), Autor and Duggan (2003), Rege et al. (2009) and Bratsberg et al. (2013). 
Peer effects may thus be relevant both for the overall SI claim propensity and for the distribution of claims across programs. By focusing on a single program only, it is impossible to distinguish peer effects on the overall use of social insurance from peer effects on the propensity to use one particular program rather than another.

The present paper adds to the existing literature in at least two ways: The first is related to the research questions: It is the first paper to address peer effects associated with all social insurance programs jointly. While our main interest lies in identifying the extent to which persons' propensities to claim social insurance benefits depend on the overall use of benefits among various peer groups, we also examine the impacts that peers' behavior have on the use of particular types of SI programs. Our second contribution relates to our empirical approach: In contrast to the existing literature, we build our identification strategy on the observed timing of SI claims, rather than on their occurrence. This approach is backed up by the use of extraordinarily flexible control functions - with up to as much as 635,000 time-varying dummy variables - arguably eliminating the influence of conceivable time varying confounding factors.

\section{Theoretical Considerations}

Social interaction models start from the idea that the preferences of individuals over alternative courses of action depend directly on the actions taken by other individuals to whom the individuals relate; see, e.g., Brock and Durlauf (2000) and Cont and Löwe (2010) for overviews. The purpose of these models is typically to characterize or to provide an explanation for group behavior which emerges from interdependencies between individuals. To illustrate, let $a_{i}$ indicate individual $i$ 's use of social insurance, and assume that the payoff function associated with this action can be decomposed into a sum of a private and a social component. Let 
$a_{i}^{0}$ denote the optimal choice in the absence of social interaction and let $j \in J$ be the set of agents that $i$ relates to. With quadratic utility, we can write

$$
U_{i}\left(a_{i} ;\left\{a_{j}, j \neq i\right\}\right)=-\pi\left(a_{i}^{0}-a_{i}\right)^{2}-\sum_{j \neq i} \gamma_{i j}\left(a_{i}-a_{j}\right)^{2}
$$

with the optimal SI claim characterized by

$$
a_{i}^{*}=\frac{1}{\pi+\sum_{j \neq i} \gamma_{i j}}\left(\pi a_{i}^{0}+\sum_{j \neq i} \gamma_{i j} a_{j}\right) .
$$

In this specification, $\pi$ reflects the marginal disutility of deviating from the private optimum and $\gamma_{i j}$ measures the marginal gain in $i$ 's utility of conforming to the action of $j$. Note that it is the actual behavior of $j$ that $i$ conforms to, and not the norms/attitudes that motivate j's behavior; hence $\gamma_{i j}$ represents what Manski (1993) refers to as endogenous interaction. While endogenous and contextual interactions both represent important social propagation mechanisms, it may be important from a policy perspective to discriminate between them, since only endogenous interactions are able to create spill-over or multiplier effects of policy interventions targeted at changing actual behavior. Formally, endogenous interactions imply that optimal choices are determined in a large simultaneous equations system, with as many equations as there are individuals.

We emphasize that SI contagion in this context does not necessarily reflect the prevalence of fraudulent claims. Both unemployment-related and disability-related SI programs involve substantial scope for subjective judgment with respect to whether or not a given health- or unemployment problem is sufficiently serious to justify benefits, and there is also considerable overlap between different programs. In addition, individuals can obviously exert more or less effort in order to prevent the need for SI to arise in the first place as well as to escape from it. Hence, even in cases with strict screening and monitoring (e.g., in the form of 
physician certification or job-search requirements), the utility (or disutility) associated with different types of benefit-recipiency matters for the realized level of claims.

Different classes of models are obtained from Equation (1) by parameterizing $\gamma_{i j}$ in different ways. For example, the choice $\gamma_{i j}=\gamma / N$, where $N$ is the size of the population (excluding i), leads to the global interaction model, where each agent's preferences are affected by the average action of all others, as in Lindbeck et al. (1999) and Glaeser et al. (2003). By contrast, local interaction models assume that social influences are mediated within confined groups, potentially differentiated by some notion of "distance" such that $\gamma_{i j}=\gamma\left(d_{i j}\right)$, where $d_{i j}$ is a measure of relational distance between $i$ and $j$. Studies on the structure of social groups show that individuals tend to interact most with other individuals who are similar to themselves; see, e.g., Marsden (1982). In empirical applications, social interactions are thus typically assumed to take place within peer groups, defined in terms of, e.g., neighborhoods, workplaces, school-classes, families, or races, often in combination with demographic factors (gender, age) and measures of “social distance” (e.g., educational attainment or "class”).

In the present paper, we focus on local interactions. Endogenous interaction effects are examined at group-levels, and group-averages are used as the central explanatory variables. This implies that the bivariate interaction effects - the direct influence of one person on another - are modeled as homogeneous within (narrowly defined) groups and inversely related to group size; i.e., $\gamma_{i j}=\gamma_{g} / N_{g}$, where $g$ denotes the group in question and $N_{g}$ is the number of group members apart from $i$. An important assumption embedded in this framework is that average distance increases with group size, ceteris paribus, such that the larger the number of peers in a particular group, the smaller is the influence exercised by each and one of them. Equation (2) can then be reformulated as 


$$
a_{i}^{*}=\frac{1}{\pi+\sum_{g} \gamma_{g}}\left(\pi a_{i}^{0}+\sum_{g} \gamma_{g} \bar{a}_{g,-i}\right),
$$

where $\gamma_{g}$ is the utility of conforming to the average behavior in group $g\left(\bar{a}_{g,-i}\right)$. This parameter clearly depends on the weight attributed by individual $i$ to the behavior of group $g$, which is again a reflection of its relational closeness, and potentially also its size. We typically expect $\gamma_{g} \geq 0$, but $\gamma_{g}<0$ can of course not be ruled out. Negative interaction effects may occur when agents derive utility from displaying novelty, as in fashion and fads, or from signaling a distance to groups one do not wish to be associated with.

\section{Institutional Setting and Data}

The Norwegian public system of social insurance is comprehensive. In the present paper, we examine all the major social insurance programs relevant for the working age population in Norway; i.e.:

- Unemployment insurance

- Sick-pay (spells exceeding 16 days only)

- Temporary disability insurance (including medical and vocational rehabilitation)

- Permanent disability insurance

- Subsidized early retirement (starting at age 62)

- Social assistance

Entitlement to unemployment insurance, sick-leave benefits and subsidized early retirement is obtained through regular employment, whereas rehabilitation benefits, disability pension, and social assistance in principle can be obtained without such experience. The replacement ratios for unemployment insurance, temporary and permanent disability, and subsidized early retirement all typically lie around $60-65 \%$ of previous earnings, but with mini- 
mum and maximum levels. For sick-leave, the replacement ratio is $100 \%$, but these benefits can only be maintained for one year (persons who are still unable to work after one year of sickness can apply for temporary or permanent disability benefits). All disability-related benefits, including sick-pay, need to be certified by a physician. Yet, in practice it has turned out to be difficult for physicians to "overrule” their clients’ own judgments; see Markussen et al. (2013). Social assistance constitutes the last layer of social insurance and is primarily targeted at individuals with no other income sources. In contrast to the other benefits, it is means tested against family income. ${ }^{1}$

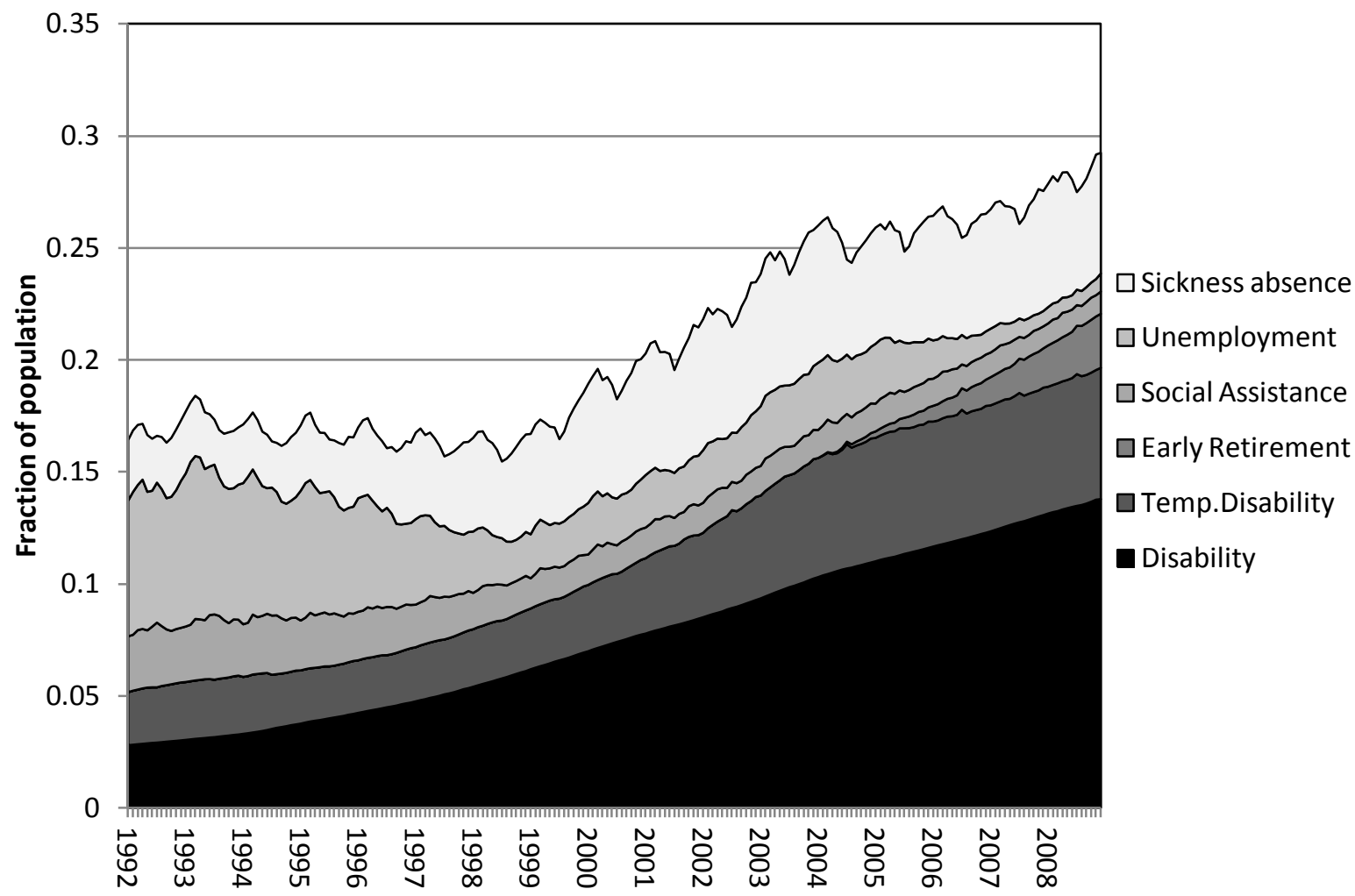

Figure 1. Social insurance claims for the 1942-1974 birth cohorts from 1992.1 to 2008.12 Note: Data include all persons who resided in Norway from 1992 to 2008 and who were born between 1942 and 1974 (1,867,662 individuals).

${ }^{1}$ Due to space considerations, we do not give a detailed description of Norwegian social insurance institutions here. More thorough descriptions (in English) are provided by Halvorsen and Stjernø (2008) and by the European Commission (2011). 
Our data cover social insurance claims for the whole Norwegian population from 1992 through 2008. Since we have chosen to use a balanced panel (see next section), we limit the analysis to individuals who were between 18 and 66 years throughout this period, implying that they were born between 1942 and 1974. This implies that our analysis comprises 33 complete birth cohorts, conditioned on being alive and residing in Norway in 1992-2008. Figure 1 gives an overview of these cohorts' social insurance claims - month by month - by SI program. Our primary interest does not lie in the use of each particular program, however, but rather in overall SI claims. This focus is partly motivated by the fact that the distinction between the different programs is blurred (Bratsberg et al., 2013), with large flows between them (Fevang et al., 2004), and partly by our ambition to identify patterns of interest beyond a narrow program-specific Norwegian setting. We are also not particularly interested in the high-frequency (month-to-month) fluctuations in SI use, which for some of the programs are dominated by seasonal factors. Hence, in the main part of our statistical analysis, we aggregate the observed social insurance outcomes into an annual dependent variable measuring the number of months with benefit claims from any of the social insurance programs in Norway. ${ }^{2}$ However, to illuminate how peers potentially affect the selection of particular SI programs, we also set up models where we distinguish the presumed disability-related programs (sickpay, temporary and permanent disability benefits, early retirement benefits) from the presumed unemployment-related programs (unemployment benefits, social assistance).

\footnotetext{
${ }^{2}$ For some of the programs, we are not able to identify accurately the dates, or the number of days, with benefit receipt; we only observe whether or not the benefit in question was received during each month.
} 

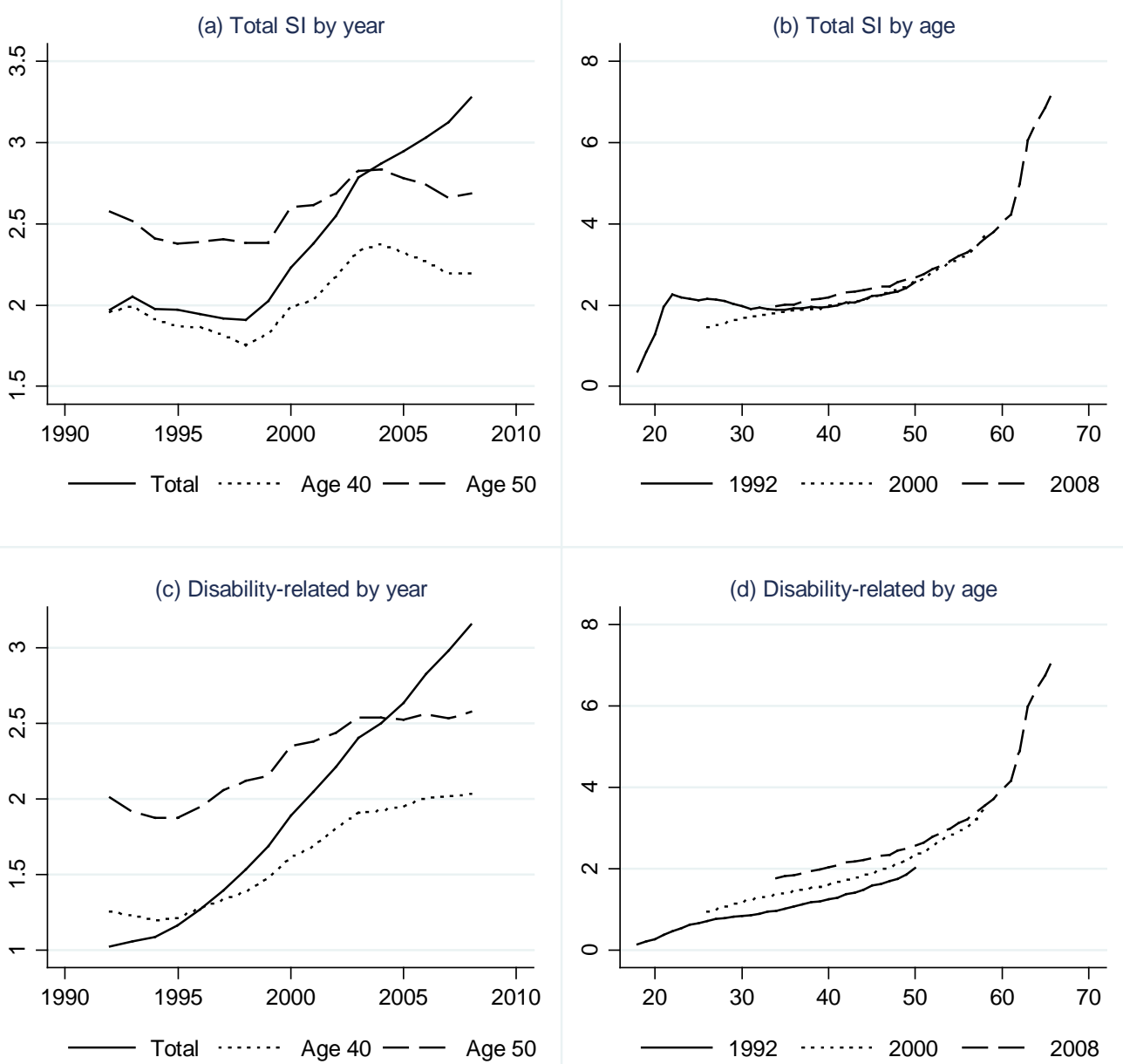

(e) Unemployment-related by year
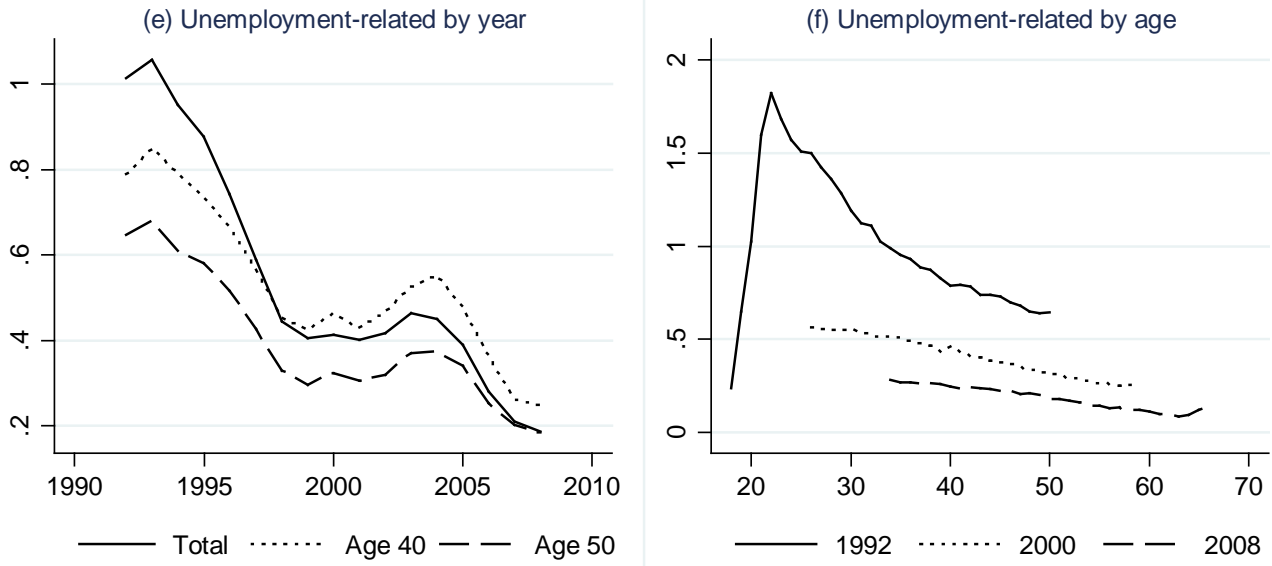

Figure 2. Number of months with SI claims in Norway, by year (1992-2008) and age (1866).

Note: Data include all persons who resided in Norway from 1992 to 2008 and who were born between 1942 and 1974 (1,867,662 individuals). 
Figure 2 illustrates some key descriptive features of the dependent variables that we are going to use in the empirical analysis. The two upper panels show how the overall use of SI developed within our analysis population from 1992 through 2008, by year and age, respectively. Since we follow the same group of people over time in this analysis, it is clear that the strong age gradient shown in panel (b) is an important factor behind the observed trend in social insurance claims shown in panel (a). This is also illustrated by the much weaker timetrend observed in panel (a) when the age-level is fixed (at age 40 and age 50, respectively). It still seems to be the case, though, that the overall SI caseloads rose significantly in the period from around 1993 to 2003, after which there was a small decline. The four lower panels illustrate the corresponding developments for disability-related and unemployment-related SI claims separately. They reveal a sharp increase in disability-related claims and a decline in unemployment-related claims.

The important role that age seems to play in the determination of individual SI claims suggests that the social interaction effects generated by a given average SI use among peers may depend on the age-composition of the peer group in question. For example, a high SI rate primarily caused by a large fraction of elderly individuals in the peer group may have a different impact on work morale than the same high rate caused by unusually high claimant rates among younger individuals. We will therefore use age-adjusted peer group averages in the statistical analyses; i.e., for each person-year in the peer group, we subtract the grand (national) age-specific mean for the year in question and then add the corresponding mean for 40year-olds. As a result, we obtain age-adjusted observations normalized to a person aged 40 .

During the period of declining unemployment and rising disability-related SI claims in the 1990's an interesting cross-sectional pattern emerged, whereby the local rises in disabilityrelated claims tended to be larger the steeper were the declines in unemployment-related claims. This is illustrated in Figure 3, where we for 1,535 local areas in Norway (to be de- 
scribed in the next section) plot the changes in average age-adjusted disability claims from 1993 to 2003 against the corresponding changes in unemployment-related claims. The marked inverse relationship between these local trends raises the question of whether a causal relationship exists. One potential source of such a relationship could be program substitution generated by "cross-program” peer effects. For example, it is conceivable that in areas with a particularly sharp decline in unemployment due to a booming labor demand, it became less attractive to present a given "labor market problem" as being caused by unemployment and more attractive to present it as being caused by poor health.

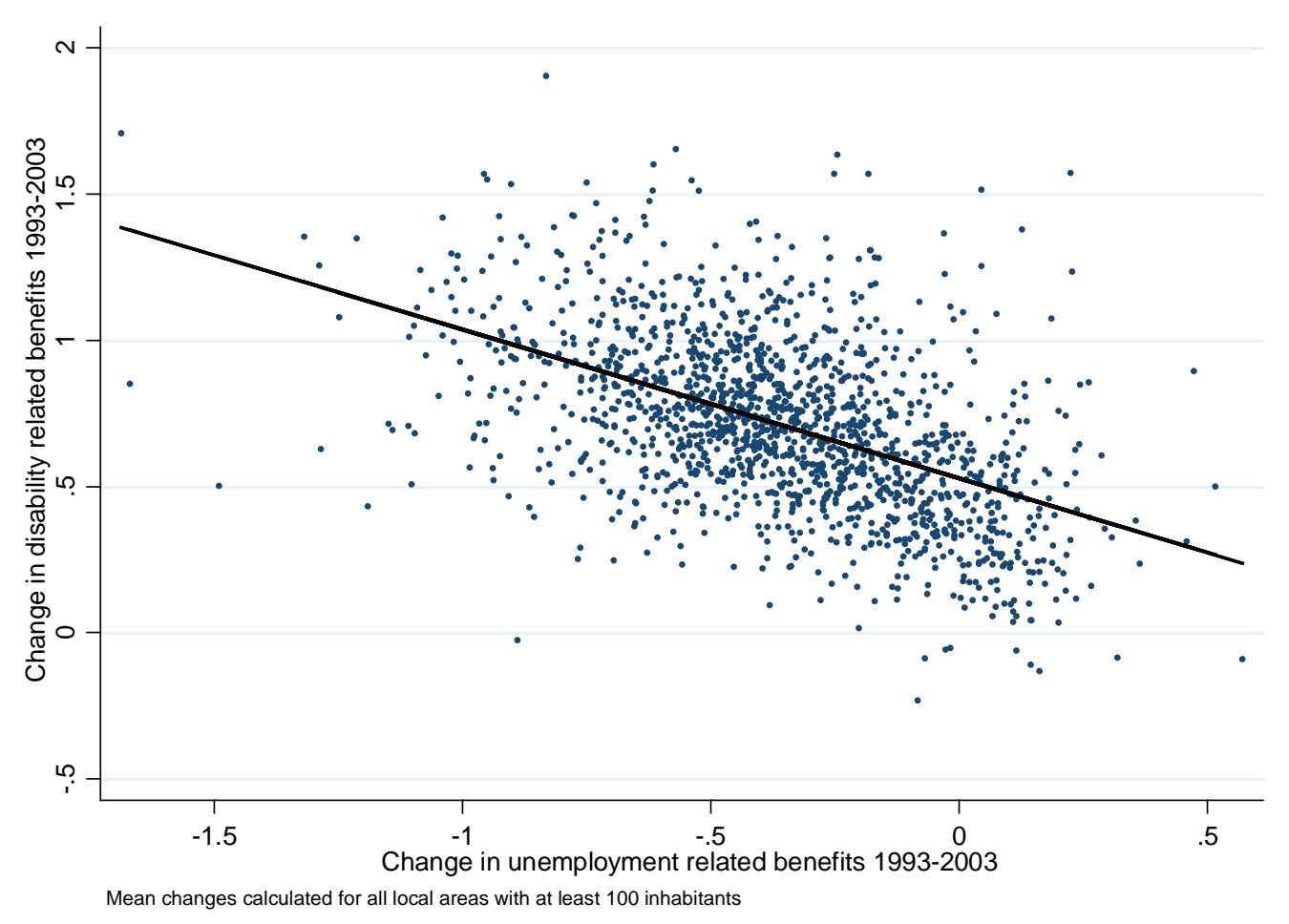

Figure 3. Changes in age-adjusted social insurance (SI) claims in 1,535 local areas in Norway.

Note: The regression line (OLS) has slope -0.50 (standard error 0.02)

\section{Empirical Analysis}

In this section, we set up linear regression models designed to find out whether - and to what extent - an individual's use of social insurance benefits is causally affected by the (ageadjusted) use within networks/groups that the individual is closely - or more vaguely - at- 
tached to. Our primary dependent variable is going to be a person-year observation reporting the number of months with SI claims, either in total or for disability- and unemploymentrelated programs separately. The key explanatory variables are the following: i) a personfixed effect, ii) the individual's own claim last year, iii) the average claims among peers last year, and iv) a vector of group-year fixed effects, where - essentially - the grouping does not coincide exactly with the peer groups. In some specifications, we also use observed timevarying variables defined at the peer-group level to account for possible confounders.

To circumvent the problem of dynamic endogenous group-formation, we focus throughout this paper on groups that - by definition - are stable; i.e., former schoolmates and persons that resided in the same geographical area at the start of our observation period. The price we pay for this is that our "networks" will serve as imperfect proxies for the various groups of people that agents actually interact with. Hence, compared to analyses based on positively identified and closely tied networks, we expect that interaction effects identified in our analysis will be significantly attenuated.

We first present the model for total SI claims. Let $y_{i, t}$ be the number of months that individual $i$ claimed (any form of) SI benefit in year $t$ and let $\bar{y}_{g,-i, t}$ be the corresponding ageadjusted SI propensity (see previous section) for persons belonging to a group $g$ in year $t$, excluding individual $i$. We set up fixed effects models of the following form:

$$
y_{i, t}=\alpha_{i}+\rho y_{i, t-1}+\lambda h_{t}\left(x_{i}\right)+\sum_{g \in G} \theta_{g} \bar{y}_{g,-i, t-1}+u_{i t},
$$

where $\alpha_{i}$ is an individual fixed effect, $h_{t}\left(x_{i}\right)$ is a time function specified separately for different combinations of individual covariates $x_{i}$, and $G$ is the set of groups/networks potentially influencing the behavior of $i$. The parameters of main interest are the $\theta_{g}{ }^{\prime} s$, which reflect the first-year peer effects. There will also be knock-on effects in subsequent years, as the first- 
year effect propagates both through the autoregressive process and through additional higherorder peer effects. The knock-on effects will decline over time provided that $\left(\theta_{g}+\rho\right)<1$. As a measure of the total cumulative peer effect, we compute the statistic

$$
\tau_{g}=\frac{\theta_{g}+\rho}{1-\theta_{g}-\rho}-\frac{\rho}{1-\rho},
$$

which represents the total number of extra SI months - over and above what arises from the autoregressive process alone - that accrues in response to a one-month transitory shock in the group average.

The individual fixed effect $\left(\alpha_{i}\right)$ is included in Equation (4) to control for sorting on overall SI-propensity into networks and for time-constant confounders. It ensures that it is the timing - not the occurrence - of SI claims within networks that identifies the effects of interest At first sight, it may appear unnecessary to use individual fixed effects in this setting, since it is confounding factors at the network level that we primarily worry about. However, without individual fixed effects, we could not have justified the critical assumption of exogenous peer behavior in year $t-1$, since it would have been affected by individual $i$ 's own (unaccounted for) SI propensity in earlier years.

The lagged dependent variable $\left(y_{i, t-1}\right)$ is included to account for the strong autocorrelation present in SI claim patterns. If unaccounted for, this pattern will cause a simultaneity problem, since a person's past SI statuses (more than one year ago) will have had a causal impact on the peers' SI statuses last year and at the same time be correlated with the individuals’ SI propensities this year.

Individual time functions $h_{t}\left(x_{i}\right)$ are included to control for time-varying confounding factors with a geographical and/or individual dimension. They are modeled as large numbers 
of group-specific time-varying dummy variables, e.g., in the form of separate time-dummies for each travel-to-work area or for each neighborhood in Norway, and/or separate timedummies for groups defined by combinations of birth-year, gender, and educational attainment. In some cases, they also include directly observed covariates, e.g., in the form of indicators for local labor market fluctuations. Their specific formulation vary across different models (as will be explained below), but they are always defined on the basis of persons' initial characteristics. We do not exploit information on e.g., migration or additional educational attainment during our observation period, as we expect that such events to some extent are endogenous responses to changes in labor market status (including transitions to social insurance dependency).

To estimate Equation (4), we use a fixed effect "within-estimator" that centers the model along several dimensions, and thus avoids estimating parameters that are not of direct interest to us. ${ }^{3}$ As a consequence, the model eventually estimated by OLS contains a residual that incorporates a covariate-adjusted individual mean (over all years), and is thus not completely exogenous with respect to the lagged dependent variable (see, e.g., Cameron and Trivedi (2005, p. 764)). Consistency requires that the average residual is small relative to each period's residual, which again requires that the number time periods is large. To assess the potential bias in our case, we have as part of a series of robustness exercises, also estimated Equation (4) with an instrumental variable (2SLS) technique proposed by Anderson and Hsiao (1981). We then rely on first-differencing (instead of mean-centering) to get rid of the person-fixed effect, and instrument the resultant lagged differences

\footnotetext{
${ }^{3}$ Due to the large number of observations (up to around 16.5 million person-years, see next section) and the large number of dummy variables (around 635,000 in the most flexible specification) in addition to the person-fixed effects, estimation raises some computational challenges. We have used a novel algorithm based on The Method of Alternating Projections as described in Gaure (2013) and implemented in the R-package "Ife"; see http://cran.r-project.org/web/packages/lfe/citation.html.
} 
$\left\{\left(y_{i, t-1}-y_{i, t-2}\right),\left(\bar{y}_{g,-i, t-1}-\bar{y}_{g,-i, t-2}\right)\right\}$ with their second lag levels $\left\{y_{i, t-2}, \bar{y}_{g,-i, t-2}\right\} \cdot{ }^{4}$ As we show below, it turns out that the first-difference 2SLS point estimates are very similar to the fixed effects OLS estimates in this case, whereas the standard errors are much larger.

To examine peers' influence on the choice of particular SI program, we also estimate models where we distinguish between the disability-related and the unemployment-related programs (see Section 4). Let $y_{i, t}^{P}$ be the number of months individual $i$ claimed benefits of type $P$ (=H(ealth), $U($ nemployment)) in year $t$. The statistical models then take the form:

$$
y_{i, t}^{P}=\alpha_{i}^{P}+\rho_{U}^{P} y_{i, t-1}^{U}+\rho_{H}^{P} y_{i, t-1}^{H}+\lambda^{P} h_{t}\left(x_{i}\right)+\sum_{g \in G}\left(\theta_{U g}^{P} \bar{y}_{g,-i, t-1}^{U}+\theta_{H g}^{P} \bar{y}_{g,-i, t-1}^{H}\right)+u_{i t}^{P}, P=H, U
$$

where $\left(\bar{y}_{g,-i, t}^{U}, \bar{y}_{g,-i, t}^{H}\right)$ are the averages (excluding individual $i$ ) in peer group $g$.

In the next subsections, we first examine interaction effects within three different types of networks separately; i.e., neighborhoods, schoolmates, and ethnic minorities. We then present a brief assessment of some underlying mechanisms, based on separate analyses of SI entry and continuation decision. In principle, we could have examined all types of networks simultaneously. However, as we explain below, the analysis of each network type requires different cuts and adaptations of the data and the models.

\subsection{Neighbors}

We start out examining the impacts of social insurance dependency within residential areas. The purpose is to examine the degree to which SI claim propensities spread endogenously within local communities and to which extent such interaction effects depend on geographical and relational distance. The latter is measured by differences in age, gender, and educational attainment. To avoid endogenous geographical sorting, our analysis is based on recorded ad-

\footnotetext{
${ }^{4}$ The reason why we also instrument the lagged differenced peer variables is that if there is a same-year peer effect in the true DGP, the differenced residual $\left(u_{i, t}-u_{i, t-1}\right)$ will be correlated with $\left(\bar{y}_{g,-i, t-1}-\bar{y}_{g,-i, t-2}\right)$.
} 
dress at the start of our analysis period; i.e., in 1992. To reduce the potential attenuation bias caused by subsequent out-migration, we limit the analysis in this subsection to persons belonging to the 1942-1960 birth cohorts, implying that they were between 32 and 50 years old - and hence reasonably settled - at the time of peer group construction in $1992 .^{5}$ We also limit the analysis to persons born in Norway, to avoid overlap with a separate analysis of the immigrant population in a later subsection.

We examine peer effects at three geographical levels; neighborhoods, local areas, and municipalities. Our definition of neighborhoods correspond to the so-called "basic statistical units” ("grunnkretser”) used by Statistics Norway. They are designed to resemble genuine neighborhoods, and contain residences that are homogeneous with respect to location and type of housing. ${ }^{6}$ There are 13,700 basic statistical units in Norway, each populated by around 350 individuals on average. Each neighborhood is part of a somewhat larger "local area". Given the geographical proximity, we would expect there to be some room for social interaction between residents of neighboring neighborhoods, although not to the same extent as for sameneighborhood residents. The local areas correspond to the so-called "statistical tracts" (“delområder”), drawn up by Statistics Norway. They are designed to encompass neighborhoods that naturally interact, e.g., by sharing common service/shopping center facilities. A typical local area comprises around 8-9 neighborhoods and 3,100 inhabitants. Local areas are again part of municipalities. There is likely to be some interaction between people leaving in different local areas in the same municipality also, but less than between people leaving in the same neighborhood or local area. A typical municipality consists of 3-4 local areas and 11,700 inhabitants.

\footnotetext{
${ }^{5}$ In our data, $58 \%$ of the individuals lived in exactly the same neighborhood in 2008 as they did in 1992.

${ }^{6}$ For a more thorough description of the neighborhood concept and other geographical entities used in this paper, see Statistics Norway (1999).
} 
It follows that we would expect genuine peer effects to be stronger within neighborhoods than within local areas, and stronger within local areas than within municipalities. To ensure that the peer groups in local areas and municipalities are directly comparable to those in the neighborhood, in terms of size as well as composition, we construct them artificially by conducting a one-to-one exact-match sampling; i.e., for each person in $i$ 's own neighborhood, we draw one person from the local area (outside own neighborhood) and one from the municipality (outside own local area), respectively, who is of the same gender, has the same age (+/one year), and has exactly the same education. ${ }^{7}$ Finally, as part of a placebo analysis, we also assemble a matched group of "peers" from a different part of the country (defined as being from a non-neighboring county).

In total, there are around 1 million individuals included in this part of the analysis, each of them contributing 16 annual observations (the 1992-observations are lost due the inclusion of the lagged variables), see Table 1 . This leaves us with a total number of more than 16 million person-year observations. On average, the persons in our dataset claim social insurance benefits in around 2.7 months each year.

Table 1. Descriptive statistics - Neighborhoods (1942-1960 cohorts)

\begin{tabular}{lc}
\hline Number of individuals & $1,035,785$ \\
Number of neighborhoods & 11,889 \\
Average size of the neighborhood (based on observations for individuals) & 364.7 \\
& 2.74 \\
Mean annual number of months with SI benefits of any kind & 2.42 \\
$\quad$ Mean annual number of months with disability-related benefits & 0.38 \\
$\quad$ Mean annual number of months with unemployment-related benefits & 18.7 \\
& 5.0
\end{tabular}

Note: The sum of months with disability- and unemployment-related benefits may exceed the total number of months, since it is possible to claim both type of benefits in the same month.

\footnotetext{
${ }^{7}$ If we find more than one match satisfying these criteria, we draw one of them randomly. If we do not find matches at all geographical levels, the person in question is dropped from the peer group ( $7.5 \%$ of individuals).
} 
In a baseline model, the vector of time-varying control variables $h_{t}\left(x_{i}\right)$ includes separate year-dummies for each travel-to-work area (TWA) in Norway and separate year-dummies for each combination of birth-year, sex, and education (the latter with 15 categories reflecting both the level and the type of education). ${ }^{8}$ There are 90 TWAs in Norway, defined by Statistics Norway to ensure that persons living in each of these areas operate in a common labor market and have, thus, been subject to the same geographical fluctuations in labor market tightness over time. However, to account for the possibility of labor market fluctuations operating at even lower geographical levels, $h_{t}\left(x_{i}\right)$ also includes indicators for neighborhoodspecific shocks. More specifically, we include an annual downsizing indicator, which is equal to one if at least two persons belonging to the same neighborhood and working in the same firm register as unemployed in the same year. To account for more general neighborhoodspecific economic fluctuations, we first compute nation-wide industry-specific annual transition rates from employment to unemployment for all Norwegian employees. ${ }^{9}$ We then use the initial (1992) employment structure in each neighborhood to compute neighborhood-specific weights. Finally, we use these weights, multiplied with the nation-wide time-varying industry specific unemployment risks to compute a variable representing the annual unemployment risks for each neighborhood.

Even with this flexible model, we still cannot rule out the occurrence of confounding shocks - in the form of unaccounted for labor market fluctuations or in the form of changes in the local SI admittance practices. In robustness exercises, we expand the model to comprise separate year dummies for each of the around 450 social insurance districts, for each of the

\footnotetext{
${ }^{8}$ With this specification, we can obviously not distinguish age from time effects, since age and time is perfectly correlated at the individual level; see Biørn et al. (2013).

${ }^{9}$ We use 12 different industries, based on ISIC codes: i) Farming and fishing, ii) Oil, gas and mining, iii) Manufacturing, iv) Electricity and water supply, v) Construction, vi) Wholesale and retail trade, hotels and restaurants, vii) Transport, storage and communication, viii) Finance, insurance and real estate, ix) Public administration and defense, $x$ ) Schools and education, xi) Health services, and xii) Other.
} 
1,700 local areas, or for each of the 4,700 family-physician practices in Norway, respectively (instead of the 90 TWAs). ${ }^{10}$

Estimation results from a set of baseline models are presented in Table 2. Looking first at the total use of SI (regardless of type) in Column I, we note that there is a significant peer effect associated with neighborhoods estimated to 0.030 . With an autoregressive coefficient equal to 0.620, this implies a cumulative peer effect (as computed in Equation (5)) around 23\%. Moving on to the neighboring neighborhoods in the local area - while maintaining the size as well as the gender-age-education-composition of the peer group - the size of the effect is cut by approximately two thirds; and moving even further away within the municipality, it becomes insignificantly different from zero. Hence, we identify a clear pattern of declining peer effects as the geographical distance increases. Looking at a matched group of artificial peers in another part of the country, the "effect" is also equal to zero. As an additional "falsification test”, we have also estimated a model where we include the behavior of the matched peer group in another part of the country as the only peer variable - i.e., as a substitute for the true peer groups. We then obtained exactly the same insignificant estimate of -0.001 (standard error 0.002), suggesting that the estimated peer effects in Table 2 do not result from unobserved shocks correlated to the gender-age-education-composition of neighborhoods.

Turning to the separate models for disability-related (Column II) and unemploymentrelated SI claims (Column III), we find that the direct (same SI type) peer effects are of similar size or larger than the total peer effects, while there are small, but significant, negative "cross effects". The latter indicates a considerable scope for substitution between the two

${ }^{10}$ Separate year-dummies for each family-physician group are included to control for possible confounding factors related to changes in the local physicians' lenience/strictness with respect to certifying disability-related SI claims. Registers with information of physician-patient-linkages are not available before 2001; hence we use the 2001 patient lists in this particular exercise. 
types of SI, and that peer behavior affects both the overall propensity to claim SI benefits and the type of benefits actually claimed.

Table 2. Main estimation results - neighborhoods (standard errors in parentheses)

\begin{tabular}{|c|c|c|c|}
\hline & $\begin{array}{c}\text { I } \\
\text { Total use of SI }\end{array}$ & $\begin{array}{c}\text { II } \\
\text { Disability- } \\
\text { related SI }\end{array}$ & $\begin{array}{c}\text { III } \\
\text { Unemployment- } \\
\text { related SI }\end{array}$ \\
\hline \multicolumn{4}{|l|}{ Total use of SI last year } \\
\hline Own claims (t-1) & $\begin{array}{c}0.620 * * * \\
(0.000)\end{array}$ & & \\
\hline \multicolumn{4}{|l|}{ Avg. claims among peers } \\
\hline Neighborhood & $\begin{array}{c}0.030 * * * \\
(0.002)\end{array}$ & & \\
\hline Local area (matched) & $\begin{array}{c}0.011 * * * \\
(0.001)\end{array}$ & & \\
\hline Municipality (matched) & $\begin{array}{c}0.002 \\
(0.003)\end{array}$ & & \\
\hline Rest of country (matched) & $\begin{array}{c}-0.001 \\
(0.002)\end{array}$ & & \\
\hline \multicolumn{4}{|l|}{ Disability-related SI last year } \\
\hline Own claims & & $\begin{array}{c}0.656 * * * \\
(0.000)\end{array}$ & $\begin{array}{l}-0.010 * * * \\
(0.000)\end{array}$ \\
\hline \multicolumn{4}{|l|}{ Avg. claims among peers } \\
\hline Neighborhood & & $\begin{array}{c}0.029 * * * \\
(0.002)\end{array}$ & $\begin{array}{l}-0.003^{* * *} \\
(0.001)\end{array}$ \\
\hline Local area (matched) & & $\begin{array}{c}0.008^{* * *} \\
(0.001)\end{array}$ & $\begin{array}{c}0.001 \\
(0.001)\end{array}$ \\
\hline Municipality (matched) & & $\begin{array}{l}0.003^{*} \\
(0.002)\end{array}$ & $\begin{array}{c}-0.002 * * \\
(0.001)\end{array}$ \\
\hline Rest of country (matched) & & $\begin{array}{c}0.000 \\
(0.002)\end{array}$ & $\begin{array}{l}-0.002 \\
(0.001)\end{array}$ \\
\hline \multicolumn{4}{|l|}{ Unemployment-related SI last year } \\
\hline Own claims & & $\begin{array}{c}0.011^{* * *} \\
(0.000)\end{array}$ & $\begin{array}{c}0.486 * * * \\
(0.000)\end{array}$ \\
\hline \multicolumn{4}{|l|}{ Avg. claims among peers } \\
\hline Neighborhood & & $\begin{array}{l}-0.006 * * * \\
(0.002)\end{array}$ & $\begin{array}{l}0.057 * * * \\
(0.002)\end{array}$ \\
\hline Local area (matched) & & $\begin{array}{c}-0.001 \\
(0.002)\end{array}$ & $\begin{array}{c}0.010^{* * *} \\
(0.001)\end{array}$ \\
\hline Municipality (matched) & & $\begin{array}{l}-0.003 \\
(0.003)\end{array}$ & $\begin{array}{c}0.008 * * * \\
(0.002)\end{array}$ \\
\hline Rest of country (matched) & & $\begin{array}{l}-0.004 \\
(0.003)\end{array}$ & $\begin{array}{c}0.002 \\
(0.002)\end{array}$ \\
\hline No. of time-varying dummy variables & 9,997 & 9,997 & 9,997 \\
\hline By geography (TWAs) & 1,336 & 1,336 & 1,336 \\
\hline $\begin{array}{l}\text { By individual characteristics (sex, } \\
\text { birth-year, education) }\end{array}$ & 8,551 & 8,551 & 8,551 \\
\hline R-squared & 0.797 & 0.822 & 0.539 \\
\hline Adj. R-squared & 0.783 & 0.810 & 0.508 \\
\hline $\mathrm{N}$ (persons) & $1,035,786$ & $1,035,786$ & $1,035,786$ \\
\hline N (person-year observations) & $16,572,676$ & $16,572,676$ & $16,572,676$ \\
\hline
\end{tabular}


As noted above, the identification of peer effects in this paper rests on the assumption that controlled for time-varying covariates, any remaining shocks in SI claims do not have a spatial pattern that coincides with our peer group definitions. While we have argued that it is hard to envisage such confounding shocks, we now examine the validity of the assumption more formally through a number of robustness analyses. In this exercise, we focus exclusively on the neighborhood peer effect on total SI use. Our strategy is to examine what happens with the estimated peer effect as we include ever more flexibility in the time-varying control functions - in the form of shocks at lower geographical levels or in the form of more differentiated geographical shocks. To check the potential bias arising from the correlation between the lagged dependent variable and the residual, we also report estimates from a first-differenced IV (2SLS) model, where the lagged differences are instrumented by their second lag levels.

Table 3. Robustness. Neighborhood peer effect on total SI use (standard errors in parentheses)

\begin{tabular}{|c|c|c|c|c|c|c|}
\hline & $\mathrm{I}$ & II & III & IV & $\mathrm{V}$ & VI \\
\hline Own claims (t-1) & $\begin{array}{c}0.620^{* * *} \\
(0.000)\end{array}$ & $\begin{array}{c}0.620^{* * *} \\
(0.000)\end{array}$ & $\begin{array}{c}0.620 * * * \\
(0.000)\end{array}$ & $\begin{array}{c}0.611^{* * *} \\
(0.000)\end{array}$ & $\begin{array}{c}0.620 * * * \\
(0.000)\end{array}$ & $\begin{array}{c}0.556^{* * *} \\
(0.001)\end{array}$ \\
\hline $\begin{array}{l}\text { Avg. claims among neighbors in own } \\
\text { neighborhood }\end{array}$ & $\begin{array}{c}0.030 * * * \\
(0.002)\end{array}$ & $\begin{array}{c}0.025^{* * *} \\
(0.002)\end{array}$ & $\begin{array}{l}0.019 * * * \\
(0.002)\end{array}$ & $\begin{array}{c}0.021^{* * *} \\
(0.002)\end{array}$ & $\begin{array}{l}0.029 * * * \\
(0.002)\end{array}$ & $\begin{array}{c}0.045^{* *} \\
(0.017)\end{array}$ \\
\hline Implied cumulative peer effect & 0.226 & 0.185 & 0.139 & 0.147 & 0.217 & 0.254 \\
\hline \multicolumn{7}{|l|}{ Geographical year dummy variables } \\
\hline TWA & 1,336 & & & & & 1,247 \\
\hline Municipality & & 6,586 & & & & \\
\hline Local area & & & 23,146 & & & \\
\hline Physician (in 2001) & & & & 57,526 & & \\
\hline Individual year dummy variables & & & & & & \\
\hline Gender×education×birth-year & 8,551 & 8,551 & 8,551 & 8,551 & & 7,981 \\
\hline \multicolumn{7}{|l|}{$\begin{array}{l}\text { Interaction of geographical and indi- } \\
\text { vidual year dummy variables }\end{array}$} \\
\hline $\begin{array}{l}\text { Gender } \times \text { education×birth- } \\
\text { year×TWA }\end{array}$ & & & & & 625,291 & \\
\hline Estimation method (OLS/2SLS) & OLS & OLS & OLS & OLS & OLS & 2SLS \\
\hline R squared & 0.797 & 0.797 & 0.797 & 0.799 & 0.804 & \\
\hline Adj. R squared & 0.783 & 0.783 & 0.783 & 0.785 & 0.783 & \\
\hline $\mathrm{N}$ (persons) & $1,035,786$ & $1,035,786$ & $1,035,786$ & 999,535 & $1,035,786$ & $1,035,786$ \\
\hline N (person-year observations) & $16,572,676$ & $16,572,676$ & $16,572,676$ & $15,992,560$ & $16,572,676$ & $15,536,040$ \\
\hline
\end{tabular}


The results from the robustness analysis are presented in Table 3. As we introduce more flexibility in the controls for local shocks, the estimated neighborhood peer effects change only a little, and all the models indicate cumulative peer effects ranging from 14 to 23 percent. This indicates that our baseline model (Column I) succeeds quite well in controlling for time-varying confounders. It is also notable that that the model's overall explanatory power - as measured by R squared - is virtually unchanged as separate year dummies are introduced at ever lower geographical levels. For example, substituting 57,526 family-physician year dummies for the 1,336 TWA year dummies raises the unadjusted R-squared from 0.797 to 0.799 . With this latter model, we also run the risk of "over-controlling", in the sense that the physician-year dummies pick up some genuine peer effects; hence it is natural to interpret the estimated peer effects for this model as a sort of lower bound.

Switching estimation technique, from fixed effects OLS to first-differenced 2SLS, does change the point estimates somewhat, with a larger first-year peer effects and a smaller autoregressive coefficient. The implied cumulative effect does not change much, however. If anything, the 2SLS-results indicate that our within-estimators underestimate the neighborhood effect slightly, although the standard errors of the 2SLS coefficients are too large to draw any firm conclusions.

Further insights to the nature of the neighborhood peer effect may be gained by assessing the importance of "relational closeness". If persons interact more with neighbors that are similar to themselves, we may hypothesize that persons are more strongly influenced by persons of same sex and similar age and education than by more dissimilar neighbors. To examine the empirical relevance of this hypothesis, we have re-estimated the baseline model for total SI claims, using a multiple of group-specific averages within own neighborhoods as explanatory variables. To ascertain direct comparability, we weight each group mean by its size 
relative to the whole neighborhood, such that each coefficient is directly comparable to the overall neighborhood effect reported in Table 2, Column I. The results are presented in Table 4. They confirm that relational closeness is important. Persons respond more strongly to the behavior of similar than dissimilar neighbors along all the three dimensions (sex, age, education). In particular, it appears that persons of similar age have much larger influence on each other than persons belonging to completely different age groups.

Table 4. Neighborhood peer effect on total SI use. By "relational closeness" (standard errors in parentheses)

\section{By sex:}

Own claims (t-1)

Average claims among peers:

Own sex

Opposite sex

By age:

Own claims (t-1)

Average claims among peers:

Younger

Same age ( \pm 5 years)

Older

\section{By education:}

Own claims (t-1)

Average claims among peers:

Lower education

Similar education (see note below)

Higher education

No. of time-varying dummy variables By geography (TWAs)

By individual characteristics (sex, birth-year, education)

R-squared

Adj. R-squared

$\mathrm{N}$ (persons)

$\mathrm{N}$ (person-year observations)

\begin{tabular}{c}
$\mathrm{I}$ \\
\hline $0.620^{* * *}$ \\
$(0.000)$ \\
\\
$0.0392^{* * *}$ \\
$(0.002)$ \\
$0.0284^{* * *}$ \\
$(0.003)$
\end{tabular}

$$
\begin{gathered}
0.622 * * * \\
(0.000) \\
\\
0.007^{*} \\
(0.004) \\
0.050^{* * *} \\
(0.003) \\
0.027 * * * \\
(0.005)
\end{gathered}
$$

$\begin{array}{ccc} & & 0.620 * * * \\ & & (0.000) \\ & & \\ & & 028 * * * \\ & (0.003) \\ & 0.039 * * * \\ & (0.003) \\ & & 0.034^{* * *} \\ & & (0.004) \\ & & \\ & & 9,887 \\ & & 1,336 \\ 9,887 & & 8,551 \\ 1,336 & & \\ 8,551 & 1,336 & 0.800 \\ & 8,551 & 0.786 \\ 0.800 & & 1,035,786 \\ 0.786 & 0.800 & 16,572,676 \\ 1,035,786 & 1,0.786 & \\ 16,572,676 & 16,572,676 & \\ \text { Less than } 11 \text { years (primary education only), } & \text { ii) } 11-13 \\ \text { versity). } & & \end{array}$




\subsection{Schoolmates}

We now turn our attention to networks consisting of persons who went to the same junior high school at the same point in time. Junior high school in Norway is a three-year track, normally attended at age 13-15. The total group of school mates during this period thus consists of five birth-cohorts; those at the same age, and those born up to two years before and two years after. We start out this section examining the peer effects present within this complete group. We then take a closer look at the importance of relational closeness, in this case measured by differences in class-levels (age) and gender. Due to data limitations, we can only use a subset of our analysis population in this section, namely those born between 1961 and 1971 (11 cohorts). To ensure that different birth-cohorts really went to a different class, we also require the group of "levelmates" to comprise at least 30 persons. Finally, we remove siblings from each person's peer group. In total, we construct data for 5,934 schoolmate groups. Descriptive statistics are provided in Table 5.

Note that common shocks related to their schooling - such as being subject to a particularly good (or bad) principal or teacher - will not represent a confounder in this analysis, since such events took place several years before our outcome period and, hence, presumably would be captured by the individual-fixed effects. It may still be the case, though, that persons who went to the same class/school are affected by the same shocks later on, as many of them continue to reside in the geographical area they grew up in. We control for this potential confounding factor in the same way as in the preceding section; i.e., by including separate year dummy variables for each travel-to-work area (TWA) based on the address recorded at the start of the outcome period. In robustness analyses, we introduce year-dummies at lower geographical levels, all the way down to the neighborhood. 
Table 5. Descriptive statistics - Schoolmates (1961-1971 cohorts)

$\begin{array}{lc}\text { Number of individuals } & 535,972 \\ \text { Number of schoolmate groups } & 5,934 \\ \text { Average number of schoolmates (taken over individuals included in the data) } & 539 \\ & 1.84 \\ \text { Mean annual number of months with SI benefits of any kind } & 1.31 \\ \quad \text { Mean annual number of months with disability-related benefits } & 0.60 \\ \quad \text { Mean annual number of months with unemployment-related benefits } & 17.6 \\ \text { Individuals with } 0 \text { benefit months all years (\%) } & 1.0 \\ \text { Individuals with } 12 \text { benefit months all years (\%) }\end{array}$

The results indicate significant peer effects among former schoolmates: see Table 6 . Looking first at the total use of SI in Column I, the peer effect is estimated to 0.056, which together with the autoregressive parameter implies a cumulative effect of $25 \%$; similar to the one we identified for neighborhoods. Moving on to the separate models for disability-related (Column II) and unemployment-related claims (Column III), we again find a pattern of positive direct effects and negative cross effects.

Table 6. Main estimation results - schoolmates (standard errors in parentheses)

\begin{tabular}{|c|c|c|c|}
\hline 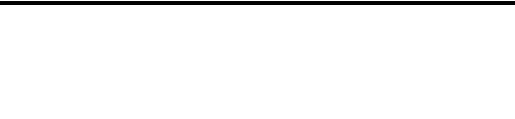 & $\begin{array}{c}\text { I } \\
\text { Total use of SI }\end{array}$ & $\begin{array}{c}\text { II } \\
\text { Disability- } \\
\text { related SI }\end{array}$ & $\begin{array}{c}\text { III } \\
\begin{array}{c}\text { Unemployment- } \\
\text { related SI }\end{array} \\
\end{array}$ \\
\hline \multicolumn{4}{|l|}{ Total use of SI last year } \\
\hline Own claims & $\begin{array}{c}0.498 * * * \\
(0.000)\end{array}$ & & \\
\hline Avg. claims among former schoolmates & $\begin{array}{c}0.056^{* * *} \\
(0.005)\end{array}$ & & \\
\hline \multicolumn{4}{|l|}{ Disability-related SI last year } \\
\hline Own claims & & $\begin{array}{c}0.588 * * * \\
(0.000)\end{array}$ & $\begin{array}{l}-0.012 * * * \\
(0.000)\end{array}$ \\
\hline Avg. claims among former schoolmates & & $\begin{array}{c}0.040 * * * \\
(0.005)\end{array}$ & $\begin{array}{l}-0.017 * * * \\
(0.004)\end{array}$ \\
\hline \multicolumn{4}{|l|}{ Unemployment-related SI last year } \\
\hline Own claims & & $\begin{array}{c}0.002 * * * \\
(0.000)\end{array}$ & $\begin{array}{c}0.404 * * * \\
(0.000)\end{array}$ \\
\hline Avg. claims among former schoolmates & & $\begin{array}{c}-0.010^{*} \\
(0.005)\end{array}$ & $\begin{array}{c}0.065^{* * * *} \\
(0.005)\end{array}$ \\
\hline No. of time-varying dummy variables & 6,917 & 6,917 & 6,917 \\
\hline By geography (TWAs) & 1,336 & 1,336 & 1,336 \\
\hline $\begin{array}{l}\text { By individual characteristics (sex, } \\
\text { birth-year, education) }\end{array}$ & 5,581 & 5,581 & 5,581 \\
\hline R-squared & 0.674 & 0.722 & 0.492 \\
\hline Adj. R-squared & 0.652 & 0.704 & 0.458 \\
\hline $\mathrm{N}$ (persons) & 534,955 & 534,955 & 534,955 \\
\hline $\mathrm{N}$ (person-year observations) & $8,559,280$ & $8,559,280$ & $8,559,280$ \\
\hline
\end{tabular}


Robustness is evaluated in Table 7, where we control for potential time-varying local confounders at lower geographical levels. The estimated peer effect decline slightly when we use separate year dummies at local area or the neighborhood levels. It is notable, though, that the estimated effects are unchanged when we substitute more than 185,000 neighborhoodyear-fixed effects for 23,000 locale-area-year-fixed effects. The estimates also change little when we use the first-differenced 2SLS estimator rather than the fixed effects OLS.

Table 7. Robustness. Schoolmate peer effect on total SI use (standard errors in parentheses)

\begin{tabular}{|c|c|c|c|c|c|}
\hline & I & II & III & IV & $\mathrm{V}$ \\
\hline Own claims (t-1) & $\begin{array}{l}0.498 * * * \\
(0.000)\end{array}$ & $\begin{array}{c}0.498 * * * \\
(0.000)\end{array}$ & $\begin{array}{l}0.497 * * * \\
(0.000)\end{array}$ & $\begin{array}{c}0.498 * * * \\
(0.000)\end{array}$ & $\begin{array}{c}0.450 * * * \\
(0.001)\end{array}$ \\
\hline Avg. claims among former schoolmates & $\begin{array}{c}0.056^{* * *} \\
(0.005)\end{array}$ & $\begin{array}{c}0.047 * * * \\
(0.005)\end{array}$ & $\begin{array}{c}0.046^{* * *} \\
(0.006)\end{array}$ & $\begin{array}{c}0.043 * * * \\
(0.006)\end{array}$ & $\begin{array}{c}0.056 * * * \\
(0.041)\end{array}$ \\
\hline Implied cumulative peer effect & 0.250 & 0.206 & 0.200 & 0.187 & 0.206 \\
\hline \multicolumn{6}{|l|}{ Geographical year dummy variables } \\
\hline TWA & 1,336 & & & & 1,247 \\
\hline Local area & & 23,446 & & & \\
\hline Neighborhood & & & 185,431 & & \\
\hline Individual year dummy variables & & & & & \\
\hline $\begin{array}{l}\text { Gender } \times \text { Education } \times \text { birth-year } \\
\text { Interaction of geographical and individ- } \\
\text { ual year dummy variables }\end{array}$ & 5,581 & 5,581 & 5,581 & & 5,209 \\
\hline $\begin{array}{l}\text { Gender } \times \text { Education } \times \text { birth- } \\
\text { year } \times \text { TWA }\end{array}$ & & & & 377,581 & \\
\hline Estimation method (OLS/2SLS) & OLS & OLS & OLS & OLS & 2SLS \\
\hline R squared & 0.674 & 0.675 & 0.682 & 0.689 & \\
\hline Adj. R squared & 0.652 & 0.652 & 0.653 & 0.652 & \\
\hline $\mathrm{N}$ (persons) & 534,955 & 534,955 & 534,955 & 534,955 & 534,955 \\
\hline N (person-year observations) & $8,559,280$ & $8,559,280$ & $8,559,280$ & $8,559,280$ & $8,024,325$ \\
\hline
\end{tabular}

Most adults probably have little (if any) contact with the majority of the persons they went to junior high-school with. Hence, by including all former schoolmates in our peer measure, we clearly include a large number of irrelevant persons. It may therefore be of some interest to distinguish "close” from more "distant” peers. In particular, we would guess that former classmates are more likely to maintain a relationship with each other than persons who went to different classes or levels. And it is also probable that same-sex persons have maintained more contact than persons of different sexes. We examine the issue of relational close- 
ness by estimating separate peer effects based on a same-level-same-sex distinction. Note that we have weighted each group's SI average with its size relative to the total number of schoolmates (all five cohorts), such that the coefficients are directly comparable to each other and to the total schoolmate effect reported in Table 7. Again, the results indicate that relational closeness is a key factor in understanding social interaction effects. The impact of samelevel-same-sex peers is much larger than the impact of other schoolmates. And for schoolmates of the opposite sex, we find no significant peer effects at all.

Table 8. Total use of SI. Estimated peer effects by relational closeness. Schoolmates. (standard errors in parentheses)

\begin{tabular}{lc}
\hline Own claims & $0.498^{* * *}$ \\
& $(0.000)$ \\
Avg. claims among former schoolmates & $0.118^{* * *}$ \\
Same level same sex & $(0.019)$ \\
& 0.018 \\
Same level opposite sex & $(0.019)$ \\
& $0.044^{* * *}$ \\
1-2 levels above/below same sex & $(0.009)$ \\
& 0.011 \\
1-2 levels above/below opposite sex & $(0.009)$ \\
& \\
No. of time-varying dummy variables & 6,917 \\
By geography (TWAs) & 1,336 \\
By individual characteristics (sex, birth-year, education) & 5,581 \\
R-squared & 0.674 \\
Adj. R-squared & 0.652 \\
N (persons) & 534,955 \\
N (person-year observations) & $8,559,280$ \\
\hline
\end{tabular}

\subsection{Ethnic minorities}

Some of the most influential existing studies on social insurance interaction effects are based on data for ethnic minorities (Bertrand et al., 2000; Aizer and Currie, 2004; Åslund and Fredriksson, 2009). We follow up on this literature by looking at SI use among immigrants from low-income countries. ${ }^{11}$ Our focus is on immigrants who reside in areas where there are sufficient numbers of other immigrants from the same country for a network of some size to be established. More specifically, we define an ethnic minority network as a group of immi-

\footnotetext{
${ }^{11}$ We disregard immigrants from high-income countries here, both because they do not tend to be concentrated in particular geographical areas and because they do not tend to reside permanently in Norway.
} 
grants from the same origin country who resided in the same local area in 1992 (the "neighborhoods" discussed above are too small for this purpose). To be included in the analysis, we require a network size of minimum 10 persons. Based on this strategy, we end up with 30,788 persons from 23 different countries, divided between 943 local immigrant networks; see Table 9 for descriptive statistics.

One could imagine that the social interaction effects decrease with geographical distance for immigrants as well as for natives, suggesting that we should examine how the estimated effects change as we substitute close groups with more distant ones (but with the same nationality). Our data impose some limitations, however, as nationality networks of the required size are typically located closely together. Instead, we use immigrants from other lowincome countries as candidates for more "distant” peers. In addition, we look at how immigrants are affected by SI use among natives within the same local area. Again, we compose the groups of other immigrants and natives such that they are of equal size and have similar characteristics as the person's own same-nationality network. We are not able to obtain exact matches of the same quality as those used in the neighborhood analysis above, and the relatively low number of observations available for this analysis also implies that we cannot "afford” to drop observations with imperfect matches. Hence, while we have a perfect matching on sex, we allow for poorer matches on age and educational attainment. We are also not able to control for time-varying confounders at a lower level than travel-to-work areas. Note, however, that immigrants from different low-income countries typically work in similar sectors of the economy, with a domination of low-skill service sector jobs (Bratsberg et al., 2010); hence if uncontrolled-for confounding factors remain at the local level, they would presumably affect persons from different low-income countries in a similar fashion. 
Table 9. Descriptive statistics - Ethnic minorities (1942-1974 cohorts)

\begin{tabular}{lc}
\hline Number of individuals & 30,788 \\
Number of immigrant networks & 943 \\
Average size of immigrant network (taken over individuals in included in the data) & 106.6 \\
& 3.41 \\
Mean annual number of months with SI benefits of any kind & 2.21 \\
$\quad$ Mean annual number of months with disability-related benefits & 1.36 \\
Mean annual number of months with unemployment-related benefits & 18.7 \\
Individuals with 0 benefit months all years (\%) & 3.0 \\
Individuals with 12 benefit months all years (\%) & \\
\hline
\end{tabular}

Table 10. Main estimation results - nationalities (standard errors in parentheses)

\begin{tabular}{lcc}
\hline & \multicolumn{2}{c}{ Total use of SI } \\
\cline { 2 - 3 } Total use of SI last year & $0.551^{* * *}$ & $0.544^{* * *}$ \\
Own claims & $(0.002)$ & $(0.006)$ \\
& & \\
Avg. claims among peers & & \\
$\quad$ Immigrants from same source coun- & $0.074^{* * *}$ & 0.073 \\
try & $(0.006)$ & $(0.047)$ \\
Immigrants from other low-income & -0.008 & -0.048 \\
country (matched) & $(0.005)$ & $(0.031)$ \\
$\quad$ Natives (matched) & $-0.017^{* *}$ & -0.061 \\
& $(0.008)$ & $(0.060)$
\end{tabular}

Disability-related SI last year

Own claims

$\begin{gathered}\text { Disability- } \\ \text { related SI }\end{gathered} \quad \begin{gathered}\text { Unemployment- } \\ \text { related SI }\end{gathered}$

Avg. claims among peers

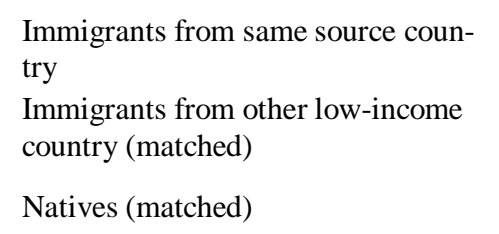

\section{Unemployment-related SI last year}

Own claims

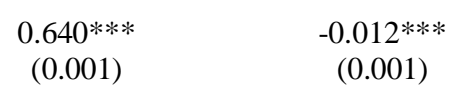

$\begin{array}{cc}0.066^{* * *} & -0.031^{* * *} \\ (0.006) & (0.006) \\ -0.001 & -0.001 \\ (0.005) & (0.006) \\ 0.002 & -0.012 \\ (0.007) & (0.008) \\ & \\ 0.006 * * * & 0.483^{* * *} \\ (0.001) & (0.001)\end{array}$

Avg. claims among peers

Immigrants from same source country

Immigrants from other low-income country (matched)

$\begin{array}{cc}-0.032 * * * & 0.132 * * * \\ (0.005) & (0.006) \\ -0.005 & -0.011 \\ (0.005) & (0.005) \\ -0.025 * * * & -0.013 \\ (0.009) & (0.009)\end{array}$

Natives (matched)

Estimation method (OLS/2SLS)

OLS 2SLS

OLS

OLS

No. of time-varying dummy variables

18,482

18,419

18,482

18,482

By geography (TWAs)

958

1,021

1,021

By individual characteristics (sex, birth-year, education)

17,461

17,461

17,461

17,461

R-squared

0.740

Adj. R-squared

0.711

0.793

0.586

$\mathrm{N}$ (persons)

30,788

0.768

0.535

492,608

30,788

30,788

30,788

$\mathrm{N}$ (person-year observations) 
Table 10 presents the results, also including the 2SLS results for the main model. According to the OLS estimates, there is a significant peer effect among immigrants from a common source country - stronger than what we have found to be the case for neighbors in general and former schoolmates. The cumulative total SI peer effect is around $44 \%$. On the other hand, we find no peer effects among immigrants from different source countries, and indications of a small negative effect of natives' SI claims. The 2SLS point estimates are almost identical to OLS for these networks, yet with much larger standard errors. Turning to the separate estimations for disability-related and unemployment related claims, we again find patterns of large positive direct effects and negative cross-effects.

\subsection{Mechanisms}

Peer effects can be driven by information-sharing and by propagation of norms/stigma. While we would expect information-sharing to be relevant for entry decisions only (or at least primarily), more general norm-effects are relevant for both entry and continuation decisions. Hence, by examining peers’ influence on entry and continuation separately we may gain some understanding of the underlying mechanisms. To do this, we have dichotomized the outcome variable used in the previous three subsections ( $=1$ for positive SI claims during a year, $=0$ otherwise), and split our dataset into three (partly overlapping) parts. To examine inflow into disability-related and unemployment-related SI, we use annual observations for which there were no SI claims last year $\left(y_{i, t-1}=0\right)$. To examine continuation of disability-related SI claims, we use observations for which there were some disability-related SI claims last year. And to examine continuation of unemployment-related SI claims, we use observations for which there were some unemployment-related claims last year (persons with both disabilityand unemployment-related claims last year are included in both the two latter groups). We then redo the main statistical analyses by program type - for neighbors, schoolmates, and ethnic minorities. Except that the lagged dependent variable drop out of the analyses, the statisti- 
cal models, the peer variables, and the control variables are exactly the same as in previous sections (conf. Tables 2, 6, and 10, respectively); i.e., OLS (in this case linear probability models) with person-fixed effects and individual time-controls (based on TWA and combinations of gender, age, and education).

Table 11. Peer effects on inflow to and continuation of SI benefit claims (standard errors in parentheses)

\begin{tabular}{|c|c|c|c|c|}
\hline & \multicolumn{2}{|c|}{ Disability-related SI } & \multicolumn{2}{|c|}{ Unemployment-related SI } \\
\hline & Inflow & Continuation & Inflow & Continuation \\
\hline \multicolumn{5}{|l|}{ Avg. claims among neighbors } \\
\hline Disability-related & $\begin{array}{c}0.0038 * * * \\
(0.0003)\end{array}$ & $\begin{array}{c}0.0031^{* * *} \\
(0.0005)\end{array}$ & $\begin{array}{c}-0.0003^{* *} \\
(0.0001)\end{array}$ & $\begin{array}{l}-0.0005 \\
(0.0017)\end{array}$ \\
\hline Unemployment-related & $\begin{array}{l}-0.0011^{* *} \\
(0.0005)\end{array}$ & $\begin{array}{c}0.0077 * * * \\
(0.0008)\end{array}$ & $\begin{array}{l}0.0022 * * * \\
(0.0002)\end{array}$ & $\begin{array}{l}0.0035^{*} \\
(0.0020)\end{array}$ \\
\hline $\mathrm{N}$ (persons) & 948,510 & 788,854 & 948,510 & 310,086 \\
\hline N (person-year observations) & $10,955,312$ & $4,832,813$ & $10,955,312$ & $4,832,813$ \\
\hline \multicolumn{5}{|c|}{ Avg. claims among school-mates } \\
\hline Disability-related & $\begin{array}{l}0.0054 * * * \\
(0.0010)\end{array}$ & $\begin{array}{l}0.0077 * * * \\
(0.0028)\end{array}$ & $\begin{array}{l}-0.0011^{*} \\
(0.0006)\end{array}$ & $\begin{array}{l}-0.0000 \\
(0.0047)\end{array}$ \\
\hline Unemployment-related & $\begin{array}{l}-0.0011 \\
(0.0011)\end{array}$ & $\begin{array}{c}0.0014 \\
(0.0032)\end{array}$ & $\begin{array}{c}0.0093^{* * *} \\
(0.0007)\end{array}$ & $\begin{array}{c}0.0169 * * * \\
(0.0041)\end{array}$ \\
\hline $\mathrm{N}$ (persons) & 518,865 & 382,052 & 518,865 & 276,190 \\
\hline N (person-year observations) & $5,980,656$ & $1,763,477$ & $5,980,656$ & $1,763,477$ \\
\hline \multicolumn{5}{|c|}{$\begin{array}{l}\text { Avg. claims among immigrants from same source } \\
\text { country }\end{array}$} \\
\hline Disability-related & $\begin{array}{c}0.0051^{* * *} \\
(0.0012)\end{array}$ & $\begin{array}{c}0.0025 \\
(0.0024)\end{array}$ & $\begin{array}{l}-0.0021^{* *} \\
(0.0009)\end{array}$ & $\begin{array}{c}0.0008 \\
(0.0033)\end{array}$ \\
\hline Unemployment-related & $\begin{array}{c}-0.0072 * * * \\
(0.0011)\end{array}$ & $\begin{array}{l}-0.0007 \\
(0.0024)\end{array}$ & $\begin{array}{l}0.0098 * * * \\
(0.0008)\end{array}$ & $\begin{array}{c}0.0082^{* * *} \\
(0.0024)\end{array}$ \\
\hline $\mathrm{N}$ (persons) & 27,775 & 20,864 & 27,775 & 19,562 \\
\hline N (person-year observations) & 274,625 & 134,020 & 274,625 & 134,020 \\
\hline
\end{tabular}

Note: Dependent variable is a dummy variable indicating whether or not SI was received at all in a given year. The peer variables are the same as those used in the previous three subsections. Control variables are also the same as those reported in Tables 2, 6, and 10, respectively.

The estimated coefficients associated with the main peer variables are presented in Table 11. Two interesting patterns emerge. The first is that the direct (same-program) peer effects are positive and significant for both entry and continuation decisions. This suggests that the peer-effects are not only driven by information-sharing; even "experienced" claimants respond to peer behavior. The second is that the negative cross-program peer effects are entirely driven by entry-decisions. For the continuation decisions, the cross-program peer effects are either positive or zero. This suggests that peers have significant influence on a new claimant's “choice” of program by sharing experiences regarding entitlement and application pro- 
cedures. But once a person has already become a claimant, the peer influences are dominated by more general work-morale effects; higher SI claims among peers increases the payoff associated with own continuation even when the increase stems from a different program type.

\section{Conclusion}

We have shown that there are significant social interaction effects in the use of social insurance (SI) benefits in Norway. Exogenous changes in SI dependency tend to be enlarged by self-enforcing group-behavior, implying the existence of a social multiplier. To avoid the problems of endogenous group formation, our analysis has been based on peer groups composed of former neighbors and schoolmates - within which the majority of the members presumably have little or no contact with each other. We nevertheless estimate cumulative knock-on effects associated with exogenous changes in SI claims within these networks amounting to at least $20 \%$. Our estimates may be interpreted as lower bounds on peer effects prevailing in more closely knitted networks of genuine friends and actually interacting neighbors.

An important finding of our paper is that peer behavior not only affects individuals' overall propensity to claim social insurance benefits, but also the type of program to which claims are directed. For example, a rise in a peer group’s disability insurance claims increases the group-members propensity to claim disability insurance, but at the same time it significantly reduces their propensity to claim unemployment benefits or social assistance (and vice versa). The negative "cross-effect” only applies to initial non-claimants, though, suggesting that the information value of experience-sharing within networks is empirically important. However, we also identify a particularly large “same-program” peer effect for already existing claimants. This suggests that more frequent use of a particular SI program within a peer group reduces the stigma associated with using that particular program, relative to the use of other 
programs. Previous empirical evidence has shown that there is indeed a significant overlap in the caseloads of different social insurance programs in Norway, and that job loss more than doubles the risk of entry into disability-related SI programs (Bratsberg et al., 2013). Our own findings provide further evidence on the substitutability between SI programs, and indicate that that the dividing line drawn between them is path dependent. They also indicate that empirical findings reported for peer effects within specific programs (see Section 2) must be interpreted with some care, as they may reflect a combination of contamination in the overall use of SI and a substitution for other SI programs.

The methodological approach used in this paper has been designed to identify and estimate local social propagation mechanisms based on the timing - rather than the occurrence of claims; and we have argued that we have done so in a way that convincingly and robustly distinguishes endogenous interactions from other sources of within-group correlations. We have identified a conspicuous tendency for estimated interaction effects to rise with measures of relational closeness in a way that, given our vector of control variables, is unlikely to have been caused by confounding shocks. Any social contagion operating at the aggregate or regional level, however, for example through an effect of overall SI propensity on the disutility/stigma of claiming SI benefits, have been effectively "controlled away” by the use of separate year dummy variables for different travel-to-work areas. We have done this not because we believe that such aggregate/regional effects are empirically irrelevant, but because we see no way to convincingly disentangle them from other sources of time changes in SI dependence rates. Indeed, we will argue that the identification of social multipliers at local levels may be indicative of such effects being present at the aggregate level as well.

The complementarities in individual behaviors exposed in our empirical analysis can potentially explain why large regional differences in SI claim patterns persist and why we sometimes witness time-trends with no apparent observed cause. In particular, they may shed 
some new light on the conspicuous (but largely unexplained) rise in Norwegian disability insurance claims between 1995 and 2004, which apparently coincided (perhaps with a small time lag) with a steep decline in unemployment insurance claims (see Figure 2, panels (c) and (e) in Section 4 above). The fall in unemployment was no doubt triggered by cyclical factors, although the results presented in this paper indicate that it may have gained momentum through social interaction effects. More importantly in the present context, it may have contributed to the subsequent rise in disability-related insurance claims, which in turn also gained momentum through self-enforcing network effects. As unemployment dropped, it became relatively more stigmatizing to claim unemployment insurance benefits, and, as a result, the demand for alternative disability-related benefits rose.

The policy implications of the endogenous social interaction effects identified in this paper are important. If governments can find ways to reduce the social insurance rolls directly - e.g., by tightening gate-keeping, increasing rehabilitation efforts, reducing benefit levels, or by expanding activation programs - they can expect a significant "bonus" reduction through the social multiplier. This implies that strategies to get individuals off the SI roll may be cost effective even when the direct costs exceed the benefits for each individual claimant. Furthermore, the mere existence of (sizeable) social interaction effects can be interpreted as evidence that moral hazard problems are empirically relevant: SI claims are not triggered by exogenous job loss or health shocks alone; they are the result of individual choices made on the basis of individual preferences. And these preferences apparently incorporate a malleable social norm.

\section{References}

Aizer, A. and Currie, J. (2004) Networks or Neighborhoods? Correlations in the Use of 
Publically-funded Maternity Care in California. Journal of Public Economics, Vol. 88, No. 12, 2573-2585.

Anderson, T. W. and Hsiao, C. (1981) Estimation of Dynamic Models with Error Components. Journal of the American Statistical Association, Vol. 76, 598-606.

Åslund, O. and Fredriksson, P. (2009) Peer Effects in Welfare Dependence. QuasiExperimental Evidence. Journal of Human Resources, Vol. 44, No. 3, 798-825.

Autor, D. and Duggan, M. G. (2003) The Rise in the Disability Rolls and the Decline in Unemployment. The Quarterly Journal of Economics, Vol. 118, 157-205.

Bertrand, M., Luttmer, E. F. P., and Mullainathan, S. (2000) Network Effects and Welfare Cultures. Quarterly Journal of Economics, Vol. 115,No. 3, 1019-1055.

Biørn, E., Gaure, S., Markussen, S., and Røed, K. (2013) The Rise in Absenteeism: Disentangling the Impacts of Cohort, Age and Time. Journal of Population Economics, Vol. 26, No. 4, 1585-1608.

Black, D., Daniel, K., and Sanders, S. (2002) The Impact of Economic Conditions on Participation in Disability Programs: Evidence from the Coal Boom and Bust. American Economic Review, Vol. 92, 27-50.

Blume, L. A., Brock, W. A., Durlauf, S. N., and Ioannides, Y. M. (2010) Identification of Social Interactions. In Benhabib, J., Bisin, A. and Jackson, M (eds.): Handbook of Social Economics. Elsevier, North-Holland.

Bradley, S., Green, C., and Leeves, G. (2007) Worker Absence and Shirking: Evidence from Matched Teacher-School Data. Labour Economics, Vol. 14, 319-334

Bratberg, E., Nilsen, Ø. A., and Vaage, K. (2012) Intergenerational correlation in disabil- 
ity benefits receipt. Working Paper 07-2012, Dept of Economics, University of Bergen.

Bratsberg, B., Fevang, E., and Røed, K. (2013) Job Loss and Disability Insurance. Labour Economics, forthcoming.

Bratsberg, B., Raaum, O., and Røed, K. (2010) When Minority Labor Migrants Meet the Welfare State. Journal of Labor Economics, Vol. 28 (2010), No. 3, 633-676.

Brock, W. A. and Durlauf, S. N. (2000) Interaction-Based Model. In Heckman, J. and Leamer, E. (Eds.) Handbook of Econometrics, Vol. 5, North-Holland.

Burkhauser, R. V. and Daly, M. C. (2011) The Declining Work and Welfare of People with Disabilities: What Went Wrong and a Strategy for Change. AEI Press, Washington D.C.

Cameron, A. C. and Trivedi, P. K. (2005) Microeconometrics - Methods and Applications. Cambridge University Press.

Conley, T. and Topa, G. (2002) Socio-Economic Distance and Spatial Patterns in Unemployment. Journal of Applied Econometrics, Vol. 17, 303-327.

Cont, R. and Löwe, M. (2010) Social Distance, Heterogeneity, and Social Interactions. Journal of Mathematical Economics, Vol. 46, 572-590.

Dahl, G. B., Kostøl, A. R., and Mogstad, M. (2013) Family Welfare Cultures. NBER Working Paper 19237.

Duggan, M. and Imberman, S. (2006) Why Are Disability Rolls Skyrocketing? In D. Cutler and D. Wise (eds.): Health in Older Ages: The Causes and Consequences of 
Declining Disability among the Elderly. University of Chicago Press.

Durlauf, S. (2004) Neighborhood Effects. In Handerson and Thisse (Eds): Handbook of Urban and Regional Economics, Vol. IV, North-Holland, Amsterdam.

Eugster, B., Lalive, R., Steinhauer, A. and Zweimüller, J. (2011) The Demand for Social Insurance: Does Culture Matter? Economic Journal, Vol. 121, F413-F448.

European Commission (2011) Your social security rights in Norway. The European Commission (http://ec.europa.eu/social-security-directory)

Fevang, E., Røed, K., Westlie, L. and Zhang, T. (2004) Veier inn i, rundt i, og ut av det norske trygde- og sosialhjelpssystemet. Rapport 6/2004, Stiftelsen Frischsenteret for samfunnsøkonomisk forskning.

Gaure, S. (2013) OLS with Multiple High Dimensional Category Variables. Computational Statistics \& Data Analysis, Vol. 66, 8-18.

Glaeser, E. L., Sacredote, B. I., and Scheinkman, J. A. (2003) The Social Multiplier. Journal of the European Economic Association, Vol. 1, No. 2-3, 345-353.

Halvorsen, K. and Stjernø, S. (2008) Work, Oil and Welfare. Universitetsforlaget, Oslo.

Hesselius, P., Johansson, P., and Nilsson, J. P. (2009) Sick of Your Colleagues' Absence? Journal of the European Economic Association, Vol. 7, No. 2-3, 583-594.

Ichino, A. and Maggi, G. (2000) Work Environment and Individual Background: Explaining Regional Shirking Differentials in a Large Italian Firm. Quarterly Journal of Economics, Vol. 115, No. 3, 1057-1090.

Ioannides, Y. M. and Loury, L. D. (2004) Job Information Networks, Neighborhood 
Interactions and Inequality. Journal of Economic Literature, Vol. 42, 1056-1093.

Lindbeck, A. (1995) Hazardous Welfare-State Dynamics, American Economic Review, Papers and Proceedings, Vol. 85, No. 2, 9-15.

Lindbeck, A., Nyberg, S. and Weibull, J. (1999) Social Norms and Economic Incentives in the Welfare State, Quarterly Journal of Economics, Vol. 114, No.1.

Lindbeck, A., Nyberg, S. and Weibull, J. (2003) Social Norms and Welfare State Dynamics, Journal of the European Economic Association, Vol. 1, pp. 533-542.

Manski, C. F. (1993) Identification of Endogenous Social Effects: The Reflection Problem. The Review of Economic Studies, Vol. 60, No. 3, 531-542.

Markussen, S., Røed, K., and Røgeberg, O. J. (2013) The Changing of the Guards: Can Physicians Contain Social Insurance Costs? IZA Discussion Paper No. 7122.

Marsden, P. V. (1982) Homogeneity in Confiding Relations. Social Networks, Vol. 10, $57-76$.

McCoy, J. L., Davis, M. and Hudson, R. E. (1994) Geographic Patterns of Disability in the United States. Social Security Bulletin, Vol. 57, No. 1, 25-36.

Moffitt, R. (1983) An Economic Model of Welfare Stigma. The American Economic Review, Vol. 73, No. 5, 1023-1035.

OECD (2010) Sickness, Disability and Work - Breaking the Barriers. A Synthesis of Findings across OECD Countries. OECD, Paris.

Rege, M., Telle, K., and Votruba, M. (2009) The Effect of Plant Downsizing on Disability Pension Utilization. Journal of the European Economic Association, Vol. 7, 
No. 5, 754-785.

Rege, M., Telle, K., and Votruba, M. (2012) Social Interaction Effects in Disability Pension Participation - Evidence from Plant Downsizing. Scandinavian Journal of Economics, Vol. 114, No. 4, 1208-1239.

Statistics Norway (1999) Regionale inndelinger - En oversikt over standarder i norsk offisiell statistikk, Norges Offisielle Statistikk, Oslo-Kongsvinger.

Stutzer, A. and Lalive, R. (2004) The Role of Social Work Norms in Job Search and Subjective Well-Being. Journal of the European Economic Association, Vol. 2, No. 4, 696-719. 